\title{
Histoire de la révolution de Naples. Ristampa anastatica della traduzione di Bertrand Barère (1807)
}

\section{Raymonde Monnier}

\section{(2) OpenEdition \\ 1 Journals \\ Édition électronique \\ URL : https://journals.openedition.org/ahrf/1864 \\ DOI : 10.4000/ahrf.1864 \\ ISSN : 1952-403X \\ Éditeur : \\ Armand Colin, Société des études robespierristes}

\section{Édition imprimée}

Date de publication : 1 décembre 2004

Pagination : 170-172

ISSN : 0003-4436

\section{Référence électronique}

Raymonde Monnier, « Histoire de la révolution de Naples. Ristampa anastatica della traduzione di Bertrand Barère (1807) », Annales historiques de la Révolution française [En ligne], 338 | octobredécembre 2004, mis en ligne le 22 mars 2006, consulté le 24 avril 2022. URL : http:// journals.openedition.org/ahrf/1864; DOI : https://doi.org/10.4000/ahrf.1864

Ce document a été généré automatiquement le 24 avril 2022.

Tous droits réservés 


\title{
Histoire de la révolution de Naples. Ristampa anastatica della traduzione di Bertrand Barère (1807)
}

\author{
Raymonde Monnier
}

\section{RÉFÉRENCE}

Vincenzo Cuoco, Histoire de la révolution de Naples. Ristampa anastatica della traduzione di Bertrand Barère (1807), Anna Maria Rao et Maïté Bouyssy (dir.), Naples, Vivarium, 2001, 416 p. [diffusion Vrin, Paris], ISBN : 88-85239-52-8. 29, $95 €$.

1 En 1807, Bertrand Barère publiait à Paris sa traduction de la seconde édition de la Saggio storico sulla rivoluzione di Napoli de Vincenzo Cuoco, parue à Milan l'année précédente, ainsi que celle du Voyage de Platon en Italie (Paris, 3 vol.) du même auteur. Un compte rendu ne peut donner qu'un aperçu de l'intérêt du texte et des introductions des deux éditrices dont la grande érudition, en replaçant le texte de Cuoco dans le contexte et la philosophie politique de l'auteur et de son traducteur, va bien au delà de l'histoire des révolutions. Mais il nous paraît important de donner un aperçu de ce livre dans notre revue, même avec un peu de retard, dans la mesure où l'édition de la Saggio storico de 1801 vient d'être publiée en édition bilingue dans la traduction française d'Alain Pons (Vincenzo Cuoco, Essai historique sur la révolution de Naples, Les Belles lettres, 2004). Les thèmes traités dans les introductions de $\mathrm{A}$. $\mathrm{M}$. Rao et de $\mathrm{M}$. Bouyssy, notamment en ce qui concerne l'étude comparée des deux traductions dues à Barère en 1807, convoquent toutes les ressources de la philosophie morale et politique du $18 \mathrm{e}$ siècle, pour comprendre cette méditation croisée sur les causes des événements révolutionnaires et la fonction du politique dans l'art de gouverner. 
2 Les orientations de l'historiographie italienne ont connu différentes phases, où le triennio, le rapport aux Lumières et à la Révolution française, le jacobinisme, ont été perçus comme le moyen de réfléchir à l'histoire nationale, au problème de l'unité italienne et de l'influence de l'Eglise. L'appréciation de l'impact de l'intervention française a renvoyé durablement aux interprétations croisées du triennio et du Risorgimento, dans une approche historique où le regard comparatif est surdéterminé par l'idée du modèle français. Un dossier présenté dernièrement dans les AHRF par Jean-Clément Martin ( $\mathrm{n}^{\circ}$ 334, p. 59-154) a montré comment les avancées de l'historiographie française sur le processus révolutionnaire dans sa durée, en nuançant le modèle d'une révolution pour l'essentiel active, ont entraîné chez les historiens italiens un regard plus complexe sur une expérience italienne longtemps qualifiée de révolution passive. Le dossier ouvert à neuf sur Barère et Cuoco par A.-M. Rao et M. Bouyssy, qui a consacré sa thèse aux textes de Barère sous la Restauration (Paris I, 1993), se place dans ces réflexions nouvelles sur le rapport entre la révolution italienne et le mouvement révolutionnaire français. Mais cette traduction s'inscrit aussi, par le jeu des regards croisés des deux exilés politiques, à l'intérieur du débat sur la philosophie de la révolution, chez des auteurs pour qui vivre libre se conçoit dans l'héritage du républicanisme, et renvoie aux débats sur les théories libérales et républicaines du début du XIXe siècle et sur le problème du politique.

3 L'interprétation de la figure politique de Cuoco dans l'historiographie italienne est caractéristique du débat toujours vif sur les Lumières et la Révolution française : après avoir été le «modéré » d'une longue tradition historiciste, Cuoco a été placé par AnnaMaria Rao dans le contexte du triennio et de l'émigration politique (1992), puis dans le cadre de son expérience politique milanaise dans la biographie d'Antonino De Francesco (1997). Or ce qui frappe à la lecture du récit circonstancié de Cuoco, c'est le patriotisme qui l'anime avec l'amour passionné de la liberté et du bien public. Profondément républicain, il n'est pas tendre pour les jacobins français et fait même au chapitre XL le procès des clubs ; pour lui les progrès du républicanisme ne pouvaient venir des «chambres patriotiques ». Est-ce simple reprise du discours thermidorien dominant ? Le terme "giacobino " a d'abord désigné les fauteurs des républiques italiennes, établies sous l'égide des armées françaises sous le Directoire, dans un temps où les jacobins en France avaient perdu le pouvoir. Le terme "patriote ", utilisé par Cuoco pour désigner les partisans de la révolution, dans sa signification primitive était synonyme de "républicain »; il s'agit du républicain au sens classique, l'homme et le citoyen vertueux « qui vole à la défense de sa patrie, remplit ses devoirs de magistrat, et cherche à se rendre utile à l'état en cultivant son esprit et son cœur » (p. 319). En cherchant à comprendre les causes de l'échec de la révolution de Naples, Cuoco poursuit un parallèle avec l'histoire de la Révolution française dont il condamne les excès : «Robespierre, en poussant la révolution au delà de toutes les bornes, ne fit qu'accélérer le discrédit de son système » (p. 177). L'expérience révolutionnaire française nourrit la phobie des extrêmes. En 1807, au moment où Napoléon recompose l'Europe sous l'autorité des napoléonides (avec Joseph sur le trône de Naples), par delà le coup de patte féroce à l'oligarchie vénitienne, la politique se décline sous le signe de la modération et de la prudence. Avec la référence à Machiavel, le concept de révolution passive peut être acceptable dans la mesure où il ouvre l'horizon rassurant d'une révolution par le haut, somme toute mesurée. Même si le récit de la révolution de Naples convoque le peuple comme principal agent de l'histoire (chap. XIX), l'idéalisme 
républicain peut s'accommoder d'un leadership héroïque et d'un art de gouverner : le talent des réformateurs consiste «à briser les liens de la dépendance ».

L'histoire comparative des révolutions ne peut se réduire au plus ou moins de succès ou à l'échec du modèle français et du jacobinisme. Certes, les peuples n'aiment pas les missionnaires armés. Mais une question essentielle demeure qui ressort de l'analyse des causes de l'échec de la république napolitaine, celle de savoir si dans l'Italie de la fin $\mathrm{du} 18 \mathrm{e}$ siècle existaient les conditions sociales et culturelles d'une rencontre heureuse entre les aspirations populaires et l'action des patriotes radicaux. Pourquoi à Naples, dernière et éphémère république née en 1799 de la fièvre qui a embrasé l'Italie, l'effort pédagogique réel des révolutionnaires pour asseoir la république sur un large consensus, n'a-t-il pu se traduire par une politique concrète dans laquelle le peuple puisse s'identifier au nouveau régime et s'impliquer activement dans la révolution? Le plus grand obstacle à l'établissement de la liberté, dit Cuoco, est qu'il n'existait pas comme en France d'identité nationale ; il y avait à Naples deux peuples distincts. Les républicains étaient "tous des meilleures familles de la capitale et des provinces ; beaucoup étaient nobles, tous étaient riches, tous pleins de lumières [...] Il désiraient le bien, mais ils ne pouvaient produire une révolution sans le concours du peuple » (p. X). Que pouvait-on espérer du langage républicain? «l'éloquence de l'école » ne pouvait avoir aucun effet sur le peuple. "Les révolutions actives sont toujours plus efficaces, parce qu'alors le peuple travaille aussitôt de lui-même à obtenir ce qui l'intéresse de plus près. Dans une révolution passive, il faut que l'agent du gouvernement devine l'esprit du peuple... » (p. 191). Or à Naples, à suivre les derniers chapitres de l'Histoire, de la mort annoncée de la révolution au bain de sang final, sur fond de rumeurs et de propagande, le drame semble se jouer dans l'incompréhension entre les élites éclairées et la «canaille ». La répression sanguinaire qui suivit la chute de la république napolitaine, dans son acharnement à détruire jusqu'aux traces de son existence, n'empêcha pas le travail de la mémoire. On conçoit comment les réflexions de Cuoco sur une politique attentive aux besoins du peuple et sur l'art de l'éloquence qui convoque toutes les ressources de la sacralité pour mettre en œuvre les énergies, ont pu entrer en résonance avec l'expérience politique de Barère, rapporteur éloquent du décret sur la levée en masse et de celui sur la Bienfaisance nationale, entre autres. Pour éveiller et soutenir l'enthousiasme pour la liberté, il faut ces médiations sensibles et immédiates avec le peuple où s'exerce l'art d'émouvoir les cœurs, cette force secrète mais irrésistible de l'éloquence populaire. Cette traduction de 1807, on le voit, va bien au delà d'une simple réflexion historique sur la révolution de Naples. 